\title{
The development of the small intestine of piglets - chosen aspects
}

\author{
M. Barszcz and J. Skomial ${ }^{1}$ \\ The Kielanowski Institute of Animal Physiology and Nutrition, \\ Polish Academy of Sciences \\ 05-110 Jabłonna, Poland
}

(Received 16 June 2010; revised version 11 January 2011; accepted 12 March 2011)

\begin{abstract}
The development of the gastrointestinal tract is a very sophisticated process, which starts during prenatal life and continues after birth. Diet is the most important factor modulating structure and functions of the intestine. In the early post-natal period the major role play bioactive substances of colostrum and milk. Their properties influence the dynamics of apoptosis and mitosis and through gastrointestinal tract development they influence animal adaptation to solid feed. The weaning period is associated with dynamic intestinal microflora development, which activity also exert a significant effect on processes taking place in the intestine. Gut function during the development and the response to feed component are often evaluated on the basis of changes in the structure of intestinal mucosa and enzyme activities. The degree of intestinal maturation influence nutrient digestibility, feed efficiency and immunity, thus greatly affecting animal production.
\end{abstract}

KEY WORDS: piglets, weaning, small intestine, development, microflora

\section{INTRODUCTION}

The development of the gastrointestinal tract (GIT) during ontogenesis is a complex process deciding about the formation of specialized intestinal epithelium that takes part in digestion and absorption of nutrients and fulfils endocrine and immunological functions. The early ontogenetic development starts during prenatal life but the most dynamic changes occur before and after birth. The whole process can be divided into five phases: 1 - morphogenesis, 2 - cytodifferentiation and

\footnotetext{
${ }^{1}$ Corresponding author: e-mail: j.skomial@ifzz.pan.pl
} 
foetal development preparing the epithelium for absorption of the colostrum and milk, 3 - birth and early suckling period, 4 - suckling period and 5 - weaning. The first two phases occur during gestation and prepare the GIT for the post-natal life. The organism of a young animal must have the ability to adaptation to changes in the diet leading to profound modifications of structure and functions of intestinal epithelium (Pacha, 2000). These modifications results in accelerated tissue growth and functional maturation and are induced by nutrients and bioactive compounds present in the colostrum and milk. These changes are mediated by hormones and nervous system (Skrzypek et al., 2005).

\section{THE DEVELOPMENT OF THE SMALL INTESTINE DURING EARLY POSTNATAL PERIOD}

Intensive growth of the piglets small intestine starts few weeks before parturition and is faster than growth of the whole organism (Sangild et al., 2000). The first ingestion of the colostrum causes acceleration in the small intestine growth, that doubles its weight and increases length by $30 \%$ within three days after birth (Xu et al., 1992). Intestinal crypts depth increases by $40 \%$ and villi height by $35 \%$ (Godlewski et al., 2005). The small intestine reaches its maximal length in the second week of life (Skrzypek et al., 2005). On the one hand growth is associated with incrustation of the mucosa by colostrum proteins and on the other hand with increased cell proliferation rate, preceded by enhanced DNA replication in mucosa (Xu et al., 2002). Stem cells, which are situated in the crypts, constitute a replication centre of the intestinal epithelium. These cells characterize by high rate of mitotic divisions. The most of cells undergo division in the middle part of the jejunum in the second day after birth. Mitotic index increases by $40-50 \%$ at this time (Biernat et al., 2003). Enhanced proliferation rate is the reason of shortening of cell renewal cycle from 20 days in the foetal intestinal epithelium to 2-3 days in the newborn tissue.

The fate of epithelial cells depends on direction of their migration. After the division some cells go down the crypts and are transformed into Paneth cells. These cells, live about 20 days, produce lysozyme and defensins and are responsible for the protection of intestinal mucosa (Verburg et al., 2000). The majority of cells go up the villous top and differentiate into enterocytes, goblet and endocrine cells. Enterocytes are the most abundant group of cells and are responsible for the secretory and absorptive functions. Goblet cells constitute approximately $5 \%$ and endocrine cells $1 \%$ of cells covering the villi. The life span of these cells rarely exceeds $48 \mathrm{~h}$ and quick turnover is based on the dynamic equilibrium between mitosis and programmed cell death type I called apoptosis. This physiological death facilitates removal of old, damaged and mutated cells during embryogenesis, development, rebuilding and involution. Maintenance of the equilibrium between 
mitosis and apoptosis allows physiological tissues rebuilding and disorders of this state contribute to many diseases (Godlewski et al., 2005). Apoptosis can be induced by different factors such as: physical (radiation, hydrostatic pressure), deficiencies of trophic and growth factors, hormones, cytokines and cytotoxic agents (ROS, enzyme inhibitors). In newly born piglets apoptotic cells occur on a whole length of the villi in contrast to adult animals, where apoptotic cells are only situated on the top of the villi. Cells are eliminated from the mucosa of newborns into the gut lumen as a single cells, group of cells or are eliminated with entire villous top. Dying cells may also be brought under the epithelium layer where they undergo phagocytosis as an apoptotic bodies. The death of cells in groups suggests that auto- and paracrine factors take part in the induction of apoptosis in the intestine of newly born piglets (Biernat et al., 2003). Moreover proximity of apoptotic cells in neighboring villi indicate on transmission of apoptotic signal in the gut lumen (Godlewski et al., 2005).

Apoptosis in the intestinal epithelium may be induced by a reduction of concentration of apoptotic proteins from Bcl-2 family, increased production of free radicals and infection. The mechanism that is probably the most important in the induction of apoptosis is a local deficiency of growth factors and tissue hormones such as: epidermal growth factor (EGF), insulin-like growth factor (IGF) and leptin (Blum and Baumrucker, 2002; Woliński et al., 2003). This pathway of apoptosis induction is important in the first few days of life when the mucosa grows very fast and the intestine has limited abilities to production of its own growth factors. Thus the intestine of newborn is very dependent on the external growth factors coming from the colostrum and milk (Guilloteau et al., 2002). Some growth factors are produced by Paneth cells, which play an important role not only in host defense but also in the development of small intestine. These factors are: intestinal trefoil factor promoting cell migration, EGF stimulating epithelial cell growth and osteopontin that regulates cell matrix interaction, polarization and migration of cells. Additionally Paneth cells are reservoir of zinc which coordinates regulation of mitosis and apoptosis and contain TNF $\alpha$ (Porter et al., 2002).

During the first days of life there is also abundant expression of transforming growth factor $\beta 1$ (TGF- $\beta 1$ ) receptor in the intestinal epithelium. TGF- $\beta 1$ is a strong inducer of death in the epithelial cells. Causing changes in the equilibrium between pro- and antiapoptotic proteins from Bcl-2 family it makes enterocytes more sensitive to death signal mediated by other cytokines such as TNF $\alpha$, which is an inducer of receptor pathway of apoptosis. Both cytokines, TGF- $\beta 1$ and TNF $\alpha$, participate in the initiation of enterocyte apoptosis (Godlewski et al., 2007).

Enhanced proliferation of stem cells in crypts increases a susceptibility on errors in replication and frequency of mutation leading to cell cycle arrest. In a situation when the error cannot be repaired a pathway of cell death dependent 
on p53 protein is trigerred (Potten et al., 1994). The role of cytokine TGF- $\beta 1$ also cannot be excluded. This cytokine is secreted by macrophages under the influence of ingested apoptotic bodies and because of its action as a paracrine factor it may also affect on neighboring cells bringing them on the receptor pathway of apoptosis (Godlewski et al., 2005, 2007).

Another form of programmed cell death is autophagy that differs from apoptosis on molecular level and in changes in cell morphology. One of the most important features of this kind of cell death is the formation of autophagolysosomes where cell organelles are degraded (Lamparska-Przybysz et al., 2005) which leads to the destruction of cell compartment without changes observed within nucleus (Bursch, 2001; Motyl et al., 2006). This pathway is catalysed by cathepsins. In comparison with apoptosis, autophagy plays a minor role in the development of the intestine. It may be switched on in cells with impaired apoptotic process (Godlewski et al., 2005; Lamparska-Przybysz et al., 2005; Motyl et al., 2006). It should be mentioned that the marker of autophagy, MAP I LC3 protein, has an affinity to the apical canalicular system (ACS) in foetal type enterocytes. The ACS consists of vacuoles similar to those which are formed during autophagy. MAP I LC3 is a part of their wall and thus increases results of autophagy evaluation. After replacement of foetal type enterocytes by adult type this marker is detected only in cells undergoing autophagy (Godlewski et al., 2007; Strzałkowski et al., 2007).

In newly born piglets increased mitosis accompanies a significant reduction of apoptosis during the first two days after birth which results in temporary increase in mitosis to apoptosis rate. This phenomenon significantly contributes to enlargement of absorptive area of intestinal mucosa. The rate of mitosis reaches the stabilization remaining until the time of weaning when another increase of cell division intensity takes place (Biernat et al., 2003). It results from the promitotic activity of some nutrients that are present in solid feed and were absent in milk, i.e. lectins. The rate of mitosis to apoptosis is a good marker of the intensity of intestine growth. It shows that the first, fast phase of post-natal growth results from both the passive incrustation of mucosa by the colostrum protein and increased number of epithelial cells. This parameter allows for the distinction of intensive intestine growth occurring during the first $24 \mathrm{~h}$ of life from intestine remodeling taking place after weaning of piglets when the mitosis to apoptosis rate do not change, despite of increased rate of mitosis (Godlewski et al., 2005).

Enhanced proliferation in the crypt area is associated with structural and functional remodeling of the epithelium. Foetal type enterocytes containing large vacuoles are replaced with cells that do not contain these vacuoles. In foetal type enterocytes there can be distinguished two types of vacuoles (Zabielski et 
al., 2008). One of them transport macromolecules in the intact form from the lumen to enterocytes (transport vacuoles). They are present in cells on the entire length of the small intestine but only within first two days after birth. Transport vacuoles allow bioactive compounds of the colostrum to go across the intestinal epithelium without an effect on their activity. The extent of this transfer is linked to passive immunity of newborns and varies between species. The specific transport of macromolecules is achieved by binding of factors present in the gut lumen to specific receptors that transport them across the epithelium protecting from intracellular hydrolysis. Intact food protein go across the epithelium through specialized $\mathrm{M}$ cells. The ability to transport macromolecules, associated with open gut barrier, decreases two days after birth (Teichberg et al., 1990; Pacha, 2000). This way of macromolecules transport occurs also in older animals but the amount of transported molecules is of signaling importance.

The other type of vacuoles (digestive or lysosomal vacuoles) are localized in cells in the further part of the small intestine and seemed to be responsible for intracellular digestion of nutrients and controlling of $\mathrm{pH}$ in the gut lumen (Baintner, 1994). These type of vacuoles plays a crucial role within first days of piglets life when the activity of gastric, pancreatic and intestinal brush border enzymes (lactase, aminopeptidase A and N, dipeptidase IV) is insufficient (Godlewski et al., 2005). Digestive vacuoles are present in the pig ileum for 3 - 4 weeks. The rate of vacuoles disappearance is strictly associated with the maturation of the intestine (Zabielski et al., 2008).

\section{MODIFICATIONS OF THE PIGLETS SMALL INTESTINE STRUCTURE DURING WEANING}

Another critical phase in the gastrointestinal tract development of young animals is the weaning period. The weaning of piglets usually takes place between 3 and 4 week of life, when the majority of nutrients is ingested with milk. Weaning is associated with mixing of piglets from different litters and sometimes also with the transport of animals from the place of birth to specialized nursery units. This results in profound social and environmental stress which is caused also by the changes in the diet. It influences piglets liveweight gain, energy metabolism and metabolic changes related to the adaptation of endocrine system (Le Dividich and Seve, 2000). After weaning intestinal environment changes drastically due to a replacement of highly digestible sow milk by solid feed, mainly of plant origin. This may lead to temporary underfeeding. The gastrointestinal tract has to adapt to the new type of feed, which leads to changes in myenteron motility, enzymes secretion and activity, and the composition of bacterial flora (Xu et al., 2000; 
Skrzypek et al., 2005). Animals failing to adapt to these changes have smaller liveweight gains, they suffer from diarrhoea and even die because of the intestinal bacteria overgrowth (Odle et al., 1996).

Profound changes in histological parameters (villous atrophy, crypts hyperplasia) and enzymatic activity of the small intestine of piglets are associated with the weaning period. These modifications are the reason of decreased digestion and nutrient absorption and contribute to the diarrhoea. Villous atrophy may result both from increased rate of cell loss leading to higher rate of mitosis in crypts and their hyperplasia and from slower rate of cell renewal resulting from the reduction of cell divisions, i.e. in case of underfeeding. Both ways are possible, but the former probably exerts stronger effect on the structure of piglet intestine (Pluske et al., 1997). During the time of weaning villous shape also undergoes modifications. It changes from finger-like to leaf- or tongue-like structures (Cera et al., 1988; Skrzypek et al., 2005).

Morphological changes in the small intestine of piglets after weaning are accompanied by smaller activity of brush border enzymes, lactase and sucrase (Pacha, 2000). The characteristical feature of weaning stress is also a rapid decline of pancreatic enzymes activity (Lindemann et al., 1986; Owsley et al., 1986) resulting in a significant reduction of apparent nutrient digestibility within the first week after weaning (Owsley et al., 1986; Le Dividich and Seve, 2000). There are also a qualitative changes in the composition of pancreatic juice. Foetal type hydrolases are replaced by their new isoforms and new hydrolytic enzymes appear, that were absent before weaning, such as protease E and elastase I (Pierzynowski et al., 1990). About two weeks are needed to restore the enzymes activity to the level before weaning. The length of this period depends on protein source in the diet and the level of dry feed intake. At the third day after weaning "noneaters" accumulate large amounts of enzymes in the pancreas without release into the gut lumen (Makkink et al., 1994). Weaning affects gene expression and enzymes synthesis in the pancreas, and the capacity of this gland to adaptation to solid feed intake by piglets (Marion et al., 2003).

\section{CHANGES IN THE INNATE BARRIER OF THE INTESTINE AND THE ROLE OF MICROFLORA IN THESE MODIFICATIONS}

The sterile gastrointestinal tract of newborns after birth is colonized with microbes coming from mother and external environment. These microorganisms affects physiological state of the gastrointestinal tract (Siggers et al., 2007). The presence of microorganisms and feed antigens is a stimulant for the development of the immune system in the intestine. The first line of defense against pathogens constitutes the mucus layer covering the intestine. The mucus consists of mucins, 
glycoproteins secreted by goblet cells as a surfactant of mucosa. They play a role in the intestinal permeability and barrier function that features change during the development. Glycoproteins, through different carbohydrate chains, prevent the adherence of bacteria and protect the deeper cells against contact with detrimental factors (Belley et al., 1999). Mucins, by the large amount of carbohydrates, create also a desirable environment for the proliferation of specific microflora. The composition of mucus plays an important role in the formation of protective barrier. Every subunits of protein core of mucins contains a central domain rich in serine, threonine, proline, alanine and glycine. Serine and threonine residues are numerous and constitute binding sites for oligosaccharide chains (Montagne et al., 2004). Threonine is of particular importance for the synthesis of mucins and constitute $30 \%$ of amino acids that build mucins. Secretion, reutilization and loss of mucins have a significant influence on the maintenance requirement on threonine. On the other hand, decreased availability of this amino acid may reduce the mucus production and negatively impaired barrier function of intestinal epithelium (Stoll, 2006; Święch et al., 2010).

Mucins can be divided into two basal groups: neutral and acidic. Among acidic mucins, sulphomucins and sialomucins can be additionally distinguished. Their names come from the chemical groups that are attached to the oligosaccharide chain (Deplancke and Gaskins, 2001). Concentrations of sulpho- and sialomucins increase together with the maturation of barrier function of newborn piglets and rats intestine (Shub et al., 1983; Turck et al., 1993). Their presence within the early post-natal development may be of particular importance for the innate barrier, because the acquired immune system is not fully developed, which makes animals more sensitive to infections (Deplancke and Gaskins, 2001).

Post-natal development is the period when changes in glycosylation of glycoproteins occur. Before weaning, most of mucins in the intestinal epithelium contains sialic acid residues which are replaced by fucose after weaning (Shub et al., 1983; Torres-Pinedo and Mahmood, 1984; Taatjes and Roth, 1990). These modifications are parallel with alterations in activities of enzymes responsible for fucosylation and sialylation (Biol et al., 1991). Both sugars, fucose and sialic acid, in the glycan chains of glycoproteins are linked to the nonreducing end of the external saccharide, which often is galactose. For the linkage of galactose to glycoproteins two galactosyltransferases are responsible. Their activities increase at the end of the third week of life (Greco et al., 2001) like the activity of fucosyltransferase. The influence of the glycan chain on the biological activity of glycoproteins is largely unknown. Differences in the composition of mucins, especially in the glycan chain, between newborn and adult rats may affect the barrier function of the intestinal epithelium (Shub et al., 1983).

Simultaneously with the growth of number of bacteria colonizing the intestine, 
the need of better protection of mucus against degradation increases. This leads to a greater production of sialomucins that are more resistant to bacterial enzymes than sulphomucins. Moreover, higher amount of goblet cells secreting acidic mucins in the ileum in comparison with the jejunum indicate that distal part of the small intestine is more susceptible to bacterial colonization. When animals become older, bacterial adhesion to mannose moieties increases. Production of neutral mucins may therefore protect against invasion of pathogenic bacteria (Forder et al., 2007).

Intestinal bacteria play a role in the regulation of epithelium rebuilding. This process is associated with a significant metabolic cost. It is very important therefore how bacteria affect cell renewal. Microorganisms may trigger the apoptosis in the intestinal epithelium in two ways. One of them is related to production of toxic metabolites such as ammonium, sulphur hydrogen and bile acids released from conjugates (Leschelle et al., 2002; Suzuki et al., 2002). The other, indirect way is based on the induction of inflammation, which increases the penetration of intraepithelial lymphocytes and the expression of cytokine TNF- $\alpha$ (Willing and Van Kessel, 2007). One of the mechanisms the animal recognizes and responds to bacteria is through toll-like receptors (TLR): TLR2, TLR4 and TLR9. These receptors respond to gram-negative bacteria, gram-positive bacteria and unmethylated CpG DNA (Medzhitov, 2001; Willing and Van Kessel, 2007). TLRs play also a role in the repair of damages of the intestine and epithelial homeostasis (Rakoff-Nahoum et al., 2004).

The main quantitative and qualitative modifications in the intestinal microflora occur in the time of weaning. New type of feed besides other nutrient contains also carbohydrates unavailable to digestive enzymes in the small intestine. This leads to a greater influx of undigested compounds to the large intestine, where they are fermented by microorganisms. The end products of bacterial fermentation are short-chain fatty acids (SCFA), mainly acetic, propionic and butyric acid. They constitute a key source of energy for covering the metabolic requirement of epithelium (Soergel, 1994). Additionally by lowering the $\mathrm{pH}$ of digesta, they facilitate the absorption of mineral complexes through the colonic mucosa (Younes et al., 1996) and prevent the development of pathogenic bacteria sensitive to increased acidity (Topping and Clifton, 2001). SCFA exert also an effect on the blood flow in the colon and the activity of myenteron in the large intestine and probably in the upper parts of the gastrointestinal tract (Topping and Clifton, 2001). SCFA stimulate the growth of epithelial cells in the ileum and large intestine (Nillson and Nyman, 2005) and increase the expression of proglucagon and secretion of glucagon-like peptide-2 (GLP-2) in the ileum. This may partially explain the trophic influence of SCFA. Recently GLP-2 is thought to be a strong modulator of growth and functions of the intestine. It belongs to the 
family of glucagon-like peptides that have many different biological functions, not only in the gastrointestinal tract, where they are synthesized, but also in the whole organism as regulators of appetite and carbohydrates metabolism (Burrin et al., 2001). One of the most important function of SCFA, especially butyrate, is a trophic effect on the intestinal epithelium. Butyric acid decreases the risk of mucosa damage and the development of cancer and ulcerative colitis.

The composition of SCFA pool depends on the type of bacteria and substrate available for fermentation. Bacterial flora of newborns fed on breast milk produce mainly acetic acid (Bullen et al., 1977), whereas the casein based milk replacers are substrates for the production of butyric and propionic acid (Pacha, 2000). The addition of fermentable carbohydrates to the diet for weaning piglets favours greater bacterial diversity and faster stabilization of microflora (Konstantinov et al., 2004). One of these carbohydrates is the resistant starch, which may change microbiological metabolism in the large intestine. The addition of resistant starch to the diet of weaning piglets strongly stimulates butyric acid production, which stimulates the large intestine growth. Greater crypts depth indicates on increased cell proliferation which corresponds with increased colon weight (Hedemann and Knudsen, 2007). Fructooligosaccharides have a similar effect. They increase butyric acid concentration in the intestinal digesta and then the number of mitotic enterocytes (Willing and Van Kessel, 2007).

Products of bacterial metabolism as well as the presence of microorganisms in the gastrointestinal tract are therefore very important for the development of intestinal epithelium and protective barrier properties.

\section{CONCLUSIONS}

During the early post-natal period the most important for the gastrointestinal tract development are bioactive compounds of colostrum and milk. Properties of these substances affect the dynamic of apoptosis and mitosis that have a key role in the rebuilding of the intestinal epithelium and animal adaptation for the ingestion of solid feed after weaning. Weaning period is associated with the dynamic development of intestinal microflora which also have a big influence on the processes taking place in the gastrointestinal tract. Functioning of the intestine during each of the developmental stages is often evaluated on the basis of changes in the structure of mucosa and enzyme activity. The appropriate gastrointestinal tract development is of significant importance for the animal production. The degree of intestinal maturity affects nutrients digestibility, feed efficiency and resistance to diseases. It can be therefore important for the results of animal performance. 


\section{REFERENCES}

Baintner K., 1994. Demonstration of acidity in intestinal vacuoles of the suckling rat and pig. J. Histochem. Cytochem. 42, 231-238

Belley A., Keller K., Gottke M., Chadee K., 1999. Intestinal mucins in colonization and host defense against pathogens. Amer. J. Trop. Med. Hyg. 60, 10-15

Biernat M., Woliński J., Godlewski M.M., Motyl T., Morisset J., Zabielski R., 2003. Apoptosis in the gut of neonatal piglets. In: Proceedings of the $9^{\text {th }}$ International Symposium on Digestive Physiology in Pigs. University of Alberta, Edmonton (Canada), pp. 46-48

Biol M.C., Pintori S., Mathian B., Louisot P., 1991. Dietary regulation of intestinal glycosyltransferase activities: relation between developmental changes and weaning in rats. J. Nutr. 121, $114-125$

Blum J.W., Baumrucker C.R., 2002. Colostral and milk insuline-like growth factors and related substances: mammary gland and neonatal (intestinal and systemic) targets. Domest. Anim. Endocrinol. 23, 101-110

Bullen C.L., Tearle P.V., Stewart M.G., 1977. The effect of "humanised" milks and supplemented breast feeding on the faecal flora of infants. J. Med. Microbiol. 10, 403-413

Burrin D.G., Petersen Y., Stoll B., Sangild P., 2001. Glucagon-like peptide 2: a nutrient-responsive gut growth factor. J. Nutr. 131, 709-712

Bursch W., 2001. The autophagosomal-lysosomal compartment in programmed cell death. Cell Death Differentiation 8, 569-581

Cera K.R., Manham D.C., Cross R.F., Reinhart G.A., Whitmoyer R.E., 1988. Effect of age, weaning and postweaning diet on small intestinal growth and jejunal morphology in young swine. $\mathrm{J}$. Anim. Sci. 66, 574-584

Deplancke B., Gaskins H.R., 2001. Microbial modulation of innate defence: goblet cells and the intestinal mucus layer. Amer. J. Clin. Nutr. 73, S1131-S1141

Forder R.E.A., Howarth G.S., Tivey D.R., Hughes R.J., 2007. Bacterial modulation of small intestinal goblet cells and mucin composition during early posthatch development of poultry. Poultry Sci. 86, 2396-2403

Godlewski M. M., Hallay N., Bierła J.B., Zabielski R., 2007. Molecular mechanism of programmed cell death in the gut epithelium of neonatal piglets. J. Physiol. Pharmacol. 58, Suppl. 3, 97-113

Godlewski M.M., Słupecka M., Woliński J., Skrzypek T., Skrzypek H., Motyl T., Zabielski R., 2005. Into the unknown - the death pathways in the neonatal gut epithelium. J. Physiol. Pharmacol. 56, Suppl. 3, 7-24

Greco S., Niepceron E., Hugueny I., George P., Louisot P., Biol M.-C., 2001. Dietary spermidine and spermine participate in the maturation of galactosyltransferase activity and glycoprotein galactosylation in rat small intestine. J. Nutr. 131, 1890-1897

Guilloteau P., Biernat M., Woliński J., Zabielski R., 2002. Gut regulatory peptides and hormones of the small intestine. In: R. Zabielski, P.C. Gregory, B. Weström (Editors). Biology of the Intestine in Growing Animals. Elsevier, Amsterdam, pp. 325-362

Hedemann M.S., Knudsen K.E.B., 2007. Resistant starch for weaning pigs - effect on concentration of short chain fatty acids in digesta and intestinal morphology. Livest. Sci. 108, 175-177

Konstantinov S.R., Favier C.F., Zhu W.Y., Williams B.A., Kluss J., Souffrant W.-B., De Vos W.M., Akkermans A.D.L., Smidt H., 2004. Microbial diversity studies of the porcine gastrointestinal ecosystem during weaning transition. Anim. Res. 53, 317-324

Lamparska-Przybysz M., Gajkowska B., Motyl T., 2005. Cathepsins and BID are involved in the molecular switch between apoptosis and autophagy in breast cancer MCF-7 cells exposed to camptothecin. J. Physiol. Pharmacol. 56, Suppl. 3, 159-179 
Le Dividich J., Seve B., 2000. Effects of underfeeding during the weaning period on growth, metabolism, and hormonal adjustments in the piglet. Domest. Anim. Endocrinol. 19, 63-74

Leschelle X., Robert V., Delpal S., Mouille B., Mayeur C., Martel P., Blachier F., 2002. Isolation of pig colonic crypts for cytotoxic assay of luminal compounds: effects of hydrogen sulfide, ammonia, and deoxycholic acid. Cell Biol. Toxicol. 18, 193-203

Lindemann M.D., Cornelius S.G., El Kandelgy S.M., Moser R.L., Pettigrew J.E., 1986. Effect of age, weaning and diet on digestive enzyme levels in the piglet. J. Anim. Sci. 62, 1298-1307

Makkink C.A., Negulescu G.P., Guixin Q., Verstegen M.W.A., 1994. Effect of dietary protein source on feed intake, growth, pancreatic enzyme activities and jejunal morphology in newly-weaned piglets. Brit. J. Nutr. 72, 353-368

Marion J., Rome V., Savary G., Thomas F., Le Dividich J., Le Huërou-Luron I., 2003. Weaning and feed intake alter pancreatic enzyme activity and corresponding mRNA levels in 7-d-old piglets. J. Nutr. 133, 362-366

Medzhitov R., 2001. Toll-like receptors and innate immunity. Nat. Rev. Immunol. 1, 135-145

Montagne L., Piel C., Lallès J.P., 2004. Effect of diet on mucin kinetics and composition: nutrition and health implications. Nutr. Rev. 62, 105-114

Motyl T., Gajkowska B., Zarzyńska J., Gajewska M., Lamparska-Przybysz M., 2006. Apoptosis and autophagy in mammary gland remodeling and breast cancer chemotherapy. J. Physiol. Pharmacol. 57, Suppl. 7, 17-32

Nillson U., Nyman M., 2005. Short-chain fatty acid formation in the hindgut of rats fed oligosaccharides varying in monomeric composition, degree of polymerisation and solubility. Brit. J. Nutr. 94, 705-713

Odle J., Zijlstra R.T., Donovan S.M., 1996. Intestinal effects of milkborne growth factors in neonates of agricultural importance. J. Anim. Sci. 74, 2509-2522

Owsley W.F., Orr D.E., Tribble L.F., 1986. Effects of nitrogen and energy source on nutrient digestibility in the young pig. J. Anim. Sci. 63, 492-496

Pacha J., 2000. Development of intestinal transport function in mammals. Physiol. Rev. 80, 16331667

Pierzynowski S.G., Weström B.R., Svendsen J., Karlsson B.W., 1990. Development of exocrine pancreas function in chronically cannulated pigs during 1-13 weeks of postnatal life. J. Pediat. Gastroenterol. Nutr. 10, 206-212

Pluske J.R., Hampson D.J., Williams I.H., 1997. Factors influencing the structure and function of the small intestine in the weaned pig: a review. Livest. Prod. Sci. 51, 215-236

Porter E.M., Bevins C.L., Ghosh D., Ganz T., 2002. The multifaceted Paneth cell. Cell. Mol. Life Sci. 59, 156-170

Potten C.S., Merritt A., Hickman J., Hall P., Faranda A., 1994. Characterization of radiation-induced apoptosis in the small intestine and its biological implications. Int. J. Radiat. Biol. 65, 71-78

Rakoff-Nahoum S., Paglino S., Eslami-Varzaneh F., Edberg S., Medzhitov R., 2004. Recognition of commensal microflora by toll-like receptors is required for intestinal homeostasis. Cell 118, 229-241

Sangild P.T., Fowden A.L., Trahair J.F., 2000. How does the foetal gastrointestinal tract develop in preparation for enteral nutrition after birth? Livest. Prod. Sci. 66, 141-150

Shub M.D., Pang K.Y., Swann D.A., Walker W.A., 1983. Age-related changes in chemical composition and physical properties of mucus glycoproteins from rat small intestine. Biochem. J. 215, 405-411

Siggers R.H., Thymann T., Siggers J.L., Schmidt M., Hansen A.K., Sangild P.T., 2007. Bacterial colonization affects early organ and gastrointestinal growth in the neonate. Livest. Sci. 109, 14-18 
Skrzypek T., Valverde Piedra J.L., Skrzypek H., Woliński J., Kazimierczak W., Szymańczyk S., Pawłowska M., Zabielski R., 2005. Light and scanning electron microscopy evaluation of the postnatal small intestinall mucosa development in pigs. J. Physiol. Pharmacol. 56, Suppl. 3, $71-87$

Soergel K.H., 1994. Colonic fermentation: metabolic and clinical implications. Clin. Invest. 72, $742-748$

Stoll B., 2006. Intestinal uptake and metabolism of threonine: nutritional impact. Adv. Pork Prod. $17,257-263$

Strzałkowski A.K., Godlewski M.M., Hallay N., Kulasek G., Gajewski Z., Zabielski R., 2007. The effect of suplementing sow with bioactive substances on neonatal small intestinal epithelium. J. Physiol. Pharmacol. 58, Suppl. 3, 115-122

Suzuki H., Yanaka A., Shibahara T., Matsui H., Nakahara A., Tanaka N., Muto H., Momoi T., Uchiyama Y., 2002. Ammonia-induced apoptosis is accelerated at higher $\mathrm{pH}$ in gastric surface mucous cells. Amer. J. Physiol. - Gastrointest. L 283, G968-G995

Święch E., Boryczka M., Taciak M., Tuśnio A., Buraczewska L., 2010. Goblet cells in the small intestine of young pigs fed low-threonine diet supplemented with threonine or with different sources of nonessential amino acids. In: Proceedings of the Symposium on Energy and Protein Metabolism and Nutrition. EAAP Publication No. 127. Parma (Italy), pp. 207-208

Taatjes D.J., Roth J., 1990. Selective loss of sialic acids from rat small intestinal epithelial cells during postnatal development: demonstration with lectin-gold techniques. Eur. J. Cell Biol. 53, 255-266

Teichberg S., Isolauri E., Wapnir R.A., Roberts B., Lifshitz F., 1990. Development of the neonatal rat small intestinal barrier to nonspecific macromolecular absorption: effect of early weaning to artificial diets. Pediat. Res. 28, 31-37

Topping D.L., Clifton P.M., 2001. Short-chain fatty acids and human colonic function: roles of resistant starch and nonstarch polysaccharides. Physiol. Rev. 81, 1031-1064

Torres-Pinedo R., Mahmood A., 1984. Postnatal changes in biosynthesis of microvillus membrane glycans of rat small intestine: evidence of a development shift from terminal sialylation to fucosylation. Biochem. Biophys. Res. Commun. 125, 546-553

Turck D., Feste A.S., Lifschitz C.H., 1993. Age and diet affect the composition of porcine colonic mucins. Pediat. Res. 33, 564-567

Verburg M., Renes I.B., Meijer H.P., Taminiau J.A.J.M., Büller H.A., Einerhand A.W.C., Dekker J., 2000. Selective sparing of goblet cells and Paneth cells in the intestine of methotrexate-treated rats. Amer. J. Physiol. - Gastrointest. L 279, G1037-G1047

Willing B.P., Van Kessel A.G., 2007. Enterocyte proliferation and apoptosis in the caudal small intestine is influenced by the composition of colonizing commensal bacteria in the neonatal gnotobiotic pig. J. Anim. Sci. 85, 3256-3266

Woliński J., Biernat M., Guilloteau P., Weström B.R., Zabielski R., 2003. Exogenous leptin controls the development of the small intestine in neonatal piglets. J. Endocrinol. 177, 215-222

Xu R.J., Mellor D.J., Tungthanathanich P., Birtles M.J., Reynolds G.W., Simpson H.V., 1992. Growth and morphological changes in the small intestine in piglets during the first three days after birth. J. Develop. Physiol. 18, 161-172

Xu R.J., Sangild P.T., Zhang Y.Q., Zhang S.H., 2002. Bioactive compounds in porcine colostrum and milk and their effects on intestinal development in neonatal pigs. In: R. Zabielski, P.C. Gregory, B. Weström (Editors). Biology of the Intestine in Growing Animals. Elsevier, Amsterdam, pp. 169-192

Xu R.J., Wang F., Zhang S.H., 2000. Postnatal adaptation of the gastrointestinal tract in neonatal pigs: a possible role of milk-borne growth factors. Livest. Prod. Sci. 66, 95-107 
Younes H., Demigne C., Remsey C., 1996. Acidic fermentation in the caecum increases absorption of calcium and magnesium in the large intestine of rat. Brit. J. Nutr. 75, 301-314

Zabielski R., Godlewski M.M., Guilloteau P., 2008. Control of development of gastrointestinal system in neonates. J. Physiol. Pharmacol. 59, Suppl. 1, 35-54 